\title{
Análisis de las fuentes de ingreso y de financiamiento del sector público no financiero (SPNF). En El Salvador período 1986-1995
}

\section{Introducción}

En el trabajo se analiza el comportamiento de los principales impuestos que sustentan los ingresos del Gobierno: Impuesto al Valor Agregado (IVA), Impuesto sobre la Renta e Impuestos al Comercio Exterior. El comportamiento de cada uno de ellos es analizado por separado y luego se cuantifica la participación de ellos en la conformación de la Carga Tributaria.

Por otra parte, también es analizada la Elasticidad y Regresividad del sistema Tributario Salvadoreño; no escapan del análisis los fenómenos de Evasión y Elusión Fiscal. El tema del Gasto Público es abordado particularmente el referente al servicio de la deuda y otros rubros que conforman el Gasto Público.

Parte sustantiva de la investigación se dedicó a estudiar las formas de financiar el Déficit Fiscal, que son de origen interno y externo. Con especial atención se estudió una forma recientemente implementada por el Gobierno, como lo son

Este articulo es un resumen del trabajo de graduación de Licenciatura en Economía, titulado "Análisis de las Fuentes de Ingreso y de Financiamiento del Sector Público No Financiero en El Salvador, periodo 1986-1995", elaborado por: Rogelio Douglas Delgado Archila, Hemán Arturo Pineda Rivas y Haydee Verónica Pereira Aguilar; alumnos de la Facultad de Ciencias Económicas de la Universidad “José Simeón Cañas".

En la investigación realizada se estudiaron las reformas a las leyes tributarias que sucedieron en El Salvador, durante 1986-1995.

Los autores expresan su agradecimiento al Lic. Ricardo Villeda y Licda. Sonia Ivett Sánchez por sus valiosas sugerencias e indicaciones, aún así los errores que quedan son exclusivamente nuestros. 
las Letras del Tesoro (LETES). Un aspecto importante investigado es el referente a las implicaciones Mactoeconomicas, según el tipo de financiamiento utilizado.

\section{Primera parte}

Los sistemas tributarios de un país se basan en tres principios: Equidad, Eficiencia Económica y Eficiencia Administrativa.

El principio de Equidad se refiere a que las personas que están en una misma situación económica deben ser gravados igualmente. El de Eficiencia Económica indica que la tributación no debe imponer costos que afecten otros objetivos, especialmente el de crecimiento económico; y el de factibilidad Administrativa, señala que los impuestos deben ser recaudados por las autoridades fiscales sin costos excesivos.

Los ingresos a la caja fiscal provienen fundamentalmente de dos tipos de fuentes: Los Ingresos Tributarios y los No Tributarios. En los primeros el contribuyente no recibe directamente una contraprestación por el pago del impuesto, y en los segundos el pago del tributo al Estado va acompañado de una contraprestación por el pago del impuesto, ejemplo: pago derechos de pasaporte.

En los países en desarrollo, como El Salvador existe otra fuente de ingresos no menos importante y son las Donaciones, que son flujos Financieros sin contrapartida, asociadas al interés político del país donante.

En los Ingresos Tributarios destacan los impuestos al Valor Agregado(IVA), Impuesto sobre la Renta y los Impuestos al Comercio Exterior.

El impuesto al Valor Agregado (IVA), es un impuesto al consumo de amplia coberturta, de relativa neutralidad, los bienes y servicios están sujetos a la misma tasa efectiva del impuesto; excepto cuando deliberadamente se aplican excensiones o tasas cero. El IVA, es un impuesto indirecto y una de sus principales desventajas es el gran número de empresas de las que el impuesto tiene que ser recolectado, lo que involucra papeleo en cálculo y verificación de créditos y deducciones.

Un segundo Ingreso Tributario es el Impuesto sobre la Renta, es un impuesto directo y concuerda con la capacidad de pago. El pago del impuesto se calcula sobre la Renta neta y se adapta con facilidad al diseño de tasas progresivas.

Una tercera fuente de Ingresos Tributarios son los Impuestos al Comercio Exterior, estos son de dos tipos: sobre las exportaciones y sobre las importaciones. En El Salvador, los impuestos a las exportaciones, su tendencia ha sido a ser derogados, y los de importación tienen como función proteger a los productores nacionales de la competencia externa. 
Cuando la suma de los Ingresos Tributarios, No Tributarios y Donaciones no son suficientes para cubrir el gasto público, surgen los Deficits Fiscales que es necesario financiar. El Financiamiento del Déficit puede ser de dos fuentes: Internas y Extemas.

El Financiamiento interno puede obtenerse con el Banco Central de Reserva y con el Sector Privado; cuando se utiliza el financiamiento del Banco Central, se afecta la base monetaria, en el corto plazo baja la tasa de interés, aumenta la demanda agregada y aparecen presiones inflacionarias.

Al utilizar el financiamiento del Sector Privado, se reduce el crédito disponible a este: se induce a la alza de la tasa de interés produciendo el efecto desplazamiento.

Cuando para financiar el Déficit se utiliza Financiamiento Externo se tiende a apreciar el tipo de cambio, hace menos competitivas las exportaciones y afecta la cuenta de servicio de factores, derivada del pago de intereses del servicio de la deuda.

\section{Segunda parte}

Análisis del comportamiento de las fuentes de ingreso y financiamiento del gasto público del SPNF en El Salvador período 1986-1996

Durante el período 1986/1996, el sistema tributario se sustentó principalmente en tres impuestos: Impuesto sobre la Renta con un promedio del $22.6 \%$, impuesto sobre el Comercio Exterior con un promedio del $22.5 \%$ y el Impuesto sobre Actos Jurídicos y Transacciones (timbres y papel sellado hasta agosto de 1992, IVA de septiembre de 1992 en adelante), con un promedio del $28.8 \%$ de 1986 a 1991 para los timbres, y de 1992 a 1995 con un promedio del 44.9\%, para 1996 alcanzo el $50.7 \%$, incremento generado por el I.V.A. sobre transacciones con el exterior (ver cuadro $\mathrm{N}^{0} 1$ ).

\section{Impuesto sobre la Renta}

En El Salvador el impuesto sobre la Renta, grava los ingresos sobre la base de renta neta, su base gravable esta compuesta por los ingresos menos los costos y las deducciones, es un impuesto de período anual; existen dos tipos de contribuyentes: las personas naturales y las personas Jurídicas. 


\section{Cuadro No 1}

Principales impuestos que sustentan los ingresos tributarios

en El Salvador 1986-1995.

Porcentajes

\begin{tabular}{|c|c|rr|c|c|c|c|}
\hline AÑOS & RENTA & \multicolumn{2}{|c|}{$\begin{array}{c}\text { COMERCIO EXTERIOR } \\
\text { Export. }\end{array}$} & $\begin{array}{c}\text { TIMBRES } \\
\text { Import }\end{array}$ & $\begin{array}{c}\text { SUB } \\
\text { IVA }\end{array}$ & $\begin{array}{c}\text { OTROS } \\
\text { TOTAL }\end{array}$ & TOTAL \\
\hline 1,986 & 16.00 & 35.7 & 7.6 & 20.70 & 80.00 & 20.00 & 100.00 \\
1,987 & 22.30 & 17.6 & 10.30 & 28.40 & 78.60 & 21.40 & 100.00 \\
1,988 & 22.10 & 14.90 & 8.40 & 28.30 & 73.70 & 26.30 & 100.00 \\
1,989 & 23.70 & 5.40 & 12.7 & 31.50 & 73.30 & 26.70 & 100.00 \\
1,990 & 22.70 & 8.00 & 14.5 & 31.80 & 77.00 & 23.00 & 100.00 \\
1,991 & 23.70 & 5.5 & 15.8 & 32.40 & 77.40 & 22.60 & 100.00 \\
1,992 & 21.60 & 0.6 & 17.4 & 40.10 & 79.90 & 20.10 & 100.00 \\
1,993 & 20.80 & 0.1 & 16.3 & 47.70 & 84.90 & 15.10 & 100.00 \\
1,994 & 23.90 & 0.00 & 16.7 & 45.90 & 86.50 & 13.50 & 100.00 \\
1,995 & 27.60 & 0.00 & 17.7 & 45.80 & 91.10 & 8.90 & 100.00 \\
1,996 & 28.80 & 0.00 & 13.48 & 50.71 & 92.99 & 7.1 & 100.00 \\
\hline
\end{tabular}

Fuente: Informes sobre gestión financiera del estado M. de Hacienda

Ley de timbres vigente hasta agosto 1992.

Ley IVA desde septiembre de 1992. Cálculos propios.

\section{Principales reformas}

En el período del presidente Duarte, en el año de 1987, mediante decreto legislativo $\mathrm{N}^{\circ} 656$ se introduce para las personas jurídicas, una modalidad llamada "pago a cuenta", con ella lo que se establece es que estas deberán pagar impuestos mensualmente del $1 \%$, sobre sus ingresos o ventas brutas.

En 1989, como parte del Programa de Ajuste Estructural, se inician reformas tendientes a modernizar al sistema tributario bajo la optica de hacer crecer el rendimiento de los impuestos y reducir costos de administración.

En 1989 se efectúan los cambios a la ley que entran en vigencia en 1990, se caracterizan por reducir los tramos para el cálculo del impuesto, así:

Personas naturales, los tramos se reducen de 24 a 7 tramos; la tasa marginal se reduce de $60 \%$ al $50 \%$ y el mínimo exento se eleva de $\emptyset 12,000.00$ a $\emptyset 18,000.00$ colones. Para las personas Jurídicas, los tramos se reducen de 5 a 3 y la tasa marginal se reduce de $35 \%$ a $30 \%$.

En 1991 se realiza otra reforma que entra en vigencia en 1992, se caracteriza al igual que la de 1989, por reducir tramos y tasa así: para las Personas Naturales, se reducen los tramos de 7 a 3, la tasa marginal se reduce del $50 \%$ al $30 \%$ y mínimo exento se eleva a $₫ 22,000.00$ colones. Y para Persona Jurídicas, se 
establece tasa marginal única del $25 \%$ y se establece mínimo imponible de \$7,000.00 colones. En 1994 se introducen modificaciones al pago a cuenta, pasa del $1 \%$ al $1.5 \%$ sobre las ventas brutas.

La intención del Gobiemo al realizar estas reformas, fue el fomentar el ahorro familiar y de las empresas, como un elemento clave de la inversión. Las tendencias crecientes de los últimos años del periodo analizado del impuesto, se debe en gran parte al aumento de la base tributaria y a mejoras en la administración de las acciones de fiscalización y recaudación de impuestos, y al comportamiento positivo de la economía Salvadoreña.

En el cuadro № 2 se indican las tendencias del Impuesto sobre la Renta y en el cuadro $\mathrm{N}^{0} 3$ se muestra la notable mejoría de la base tributaria.

\section{Cuadro № 2}

Estructura de los ingresos por impuesto sobre la renta en El Salvador.1986-1996.

(Millones de colones)

\begin{tabular}{|c|cc|c|c|c|}
\hline AÑ̃S & \multicolumn{2}{|c|}{$\begin{array}{c}\text { PERSONAS NATURALES } \\
\text { Asel. } \\
\text { Diversas }\end{array}$} & $\begin{array}{c}\text { SUB } \\
\text { Rentas }\end{array}$ & $\begin{array}{c}\text { PERSONAS } \\
\text { JURIDICAS }\end{array}$ & TOTAL \\
\hline 1986 & ND & ND & 183.3 & 249.5 & 432.8 \\
1987 & ND & ND & 199.1 & 361.4 & 560.5 \\
1988 & 163.8 & 47.3 & 211.1 & 349.7 & 560.8 \\
1989 & 198.7 & 54.0 & 252.7 & 328.6 & 581.4 \\
1990 & 215.4 & 63.6 & 279.0 & 446.5 & 725.5 \\
1991 & 284.5 & 84.6 & 368.3 & 592.5 & 960.8 \\
1992 & 315.1 & 79.9 & 395.0 & 666.8 & 1061.8 \\
1993 & 476.5 & 43.6 & 520.1 & 737.1 & 1257.2 \\
1994 & 565.2 & 352.0 & 917.2 & 885.5 & 1802.7 \\
1995 & 340.3 & 838.2 & 1178.5 & 1588.0 & 2766.5 \\
1996 & 438.0 & 658.8 & 1096.8 & 1917.6 & 3014.4 \\
\hline
\end{tabular}

Fuente: Informes anuales de la gestión financiera del estado. Ministerio de Hacienda. 


\section{Cuadro $\mathbf{N}^{\circ} 3$}

Distribución geográfica de contribuyentes del impuesto sobre la renta y renta recaudada

\begin{tabular}{|c|c|c|c|}
\hline $\begin{array}{l}\text { AÑOS } \\
N^{\top} \text { CONTRIBUY. }\end{array}$ & 1993 & 1994 & 1995 \\
\hline SANTA ANA & 2853 & 3362 & 3470 \\
\hline SAN MIGUEL & 1899 & 2223 & 2289 \\
\hline LA LIBERTAD & 3645 & 4073 & 4032 \\
\hline SAN SALVADOR & 21741 & 23429 & 22579 \\
\hline OTROS & 10684 & 67099 & 89132 \\
\hline TOTAL & 40822 & 100377 & 121502 \\
\hline RENTA RECAU. & \& 1257.0 mill. & c 1802.0 mill. & \& 2766.0 mill. \\
\hline
\end{tabular}

Fuente: Dirección General de Impuestos Internos, M. de Hacienda.

Análisis del comportamiento del ingreso por impuesto sobre el patrimonio y transferencia de bienes y raíces

Este impuesto se clasifica como un impuesto directo ya que grava la riqueza de las personas. Para una mejor exposición se presenta por separado el Impuesto al Patrimonio y el Impuesto a la Transferencia de Bienes Raíces.

\section{Cuadro N2 4 \\ Composición del ingreso por impuesto al patrimonio y transferencia de porpiedades \\ (Millones de colones)}

\begin{tabular}{|c|c|c|c|}
\hline AÑOS & PATRIMONIO & $\begin{array}{c}\text { TRANSFERENCLA } \\
\text { PROPIEDADES }\end{array}$ & TOTAL \\
\hline 1986 & 57.1 & 35.8 & 92.9 \\
1987 & 108.6 & 42.0 & 150.6 \\
1988 & 119.8 & 58.5 & 178.3 \\
1989 & 118.8 & 57.8 & 176.3 \\
1990 & 124.9 & 72.3 & 197.2 \\
1991 & 169.0 & 97.4 & 266.4 \\
1992 & 168.0 & 149.3 & 317.3 \\
1993 & 151.2 & 104.6 & 255.8 \\
1994 & 176.1 & 127.8 & 303.9 \\
1995 & 1.0 & 109.1 & 110.1 \\
\hline
\end{tabular}

Fuente: Informes de la Gestión Financiera del Estado M. de Hacienda. 
En el periodo de análisis, el Impuesto al Patrimonio sufrió reformas, así:

En 1989 se reducen los tramos a 4 y se eleva el piso para declarar a un piso de $\emptyset 300,000.00$, con una tasa marginal del $0.5 \%$ al $2.0 \%$ para las personas naturales. Para las personas jurídicas se establece un piso de $₫ 500,000.00$ con una tasa marginal de $0.9 \%$ al $2 \%$, además se establecen 3 tramos.

En abril de 1984 según decreto $\mathbf{N}^{\circ}$ 871, se deroga la ley del Impuesto al Patrimonio. En 1993 se deroga la ley del Impuesto sobre Donaciones y Sucesiones, quedando vigente el Impuesto de Transferencia a Titulo Oneroso.

\section{Análisis del comportamiento del ingreso por impuesto al comercio exterior}

El comercio exterior, como fuente de ingreso ributario tiene dos componentes: a) Impuesto a la Exportación y b) Impuesto a la Importación.

En cuanto a los impuestos de exportación en el período de estudio, se realizaron reformas tendientes a eliminarlos. Es así como en 1989 se derogan los impuestos a la exportación del café.

\section{Cuadro N 5}

Composición de los ingresos por impuestos al comercio exterior en El Salvador . 1986-1996, y \% de aporte de los ingresos tributarios.

(Millones de colones)

\begin{tabular}{|c|c|c|c|c|c|}
\hline AÑOS & EXPORT. & IMPORT. & TOTAL & TRIBU T & INGRESOS (\%) \\
\hline 1986 & 964.3 & 204.1 & 1168.4 & 2.702 .3 & 43.2 \\
1987 & 442.9 & 258.6 & 701.5 & 2.517 .0 & 27.8 \\
1988 & 377.8 & 214.3 & 592.1 & 2.539 .6 & 23.3 \\
1989 & 132.8 & 312.8 & 445.6 & 2.457 .3 & 18.1 \\
1990 & 255.4 & 464.8 & 720.2 & 3.200 .7 & 22.5 \\
1991 & 221.8 & 641.8 & 863.6 & 4.057 .1 & 21.3 \\
1992 & 28.4 & 847.0 & 875.4 & 4.880 .6 & 17.9 \\
1993 & 8.6 & 983.4 & 992.0 & 6.033 .7 & 16.4 \\
1994 & 0.2 & 1261.1 & 1261.3 & 7.547 .0 & 16.7 \\
1995 & 0.4 & 1769.1 & 1769.5 & 10.011 .7 & 17.6 \\
1996 & 0.0 & 1395.3 & 1395.3 & $10,465.1$ & 13.3 \\
\hline
\end{tabular}

Fuente: Informes de la Gestión Financiera del Estado.

El propósito de estas reformas a los impuestos de exportación, es mejorar la competitividad de estos productos en el mercado internacional. En cuanto a los impuestos de Importación, en El Salvador han sucedido reformas, así: en 1989 por resolución № 224 los ramos de Economía y Hacienda, se modifican los aranceles, se establecieron 7 tarifas entre el $5 \%$ y el $50 \%$, sustituyendo a 18 tarifas que oscilaban entre $105 \%$ y $290 \%$. 
Las reformas pretenden aranceles uniformes y de fácil aplicación, en general el comportamiento de los ingresos guarda relación directa con los volúmenes importados.

\section{Análisis del comportamiento del impuesto al consumo.}

Los impuestos al consumo en El Salvador, durante el periodo de análisis (1986-1995), han tenido dos modalidades; la primera se basa en uso de impuestos de Timbres y Papel Sellado, la segunda es la utilización del Impuesto al Valor Agregado.(IVA); ambas formas se tipifican como impuestos indirectos, por lo tanto se puede utilizar también para valorizar la regresividad del sistema tributario en su conjunto.

Las reformas a los impuestos al consumo en el período de análisis, se inician en 1987, con el decreto legislativo $\mathbf{N}^{\circ} 284$ que modifica la ley del papel sellado y timbres, modificando los procedimientos de aplicación. En 1989 se reforma nuevamente la referida ley generalizando la tasa a un $5 \%$.

Un año crucial para el Sistema Tributario Salvadoreño es en 1992, pese a la oposición de los sectores sociales de bajos ingresos se decreta en julio de 1992 la ley del IVA, con tasa del $10 \%$, que entra en vigencia en septiembre del mismo año.

El impacto del rendimiento del IVA, se puede observar entre los años 19941996, ya que en términos absolutos generó $₫ 1,125$. Millones de colones mas.

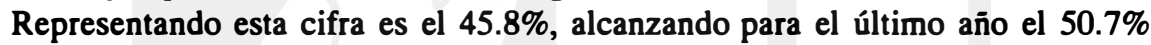
de los ingresos tributarios totales, el comportamiento del impuesto al consumo lo indica el cuadro $\mathrm{N}^{2} 6$.

\section{Cuadro N2 6}

Participación del ingreso, por impuesto al consumo en los ingresos tributarios. El Salvador.

Millones de colones

\begin{tabular}{|c|c|c|c|}
\hline AÑOS & $\begin{array}{l}\text { IMPUESTO } \\
\text { AL CONSUMO* }\end{array}$ & $\begin{array}{c}\text { INGRESOS } \\
\text { TRIBUTARIOS }\end{array}$ & $\begin{array}{c}\text { \% DE } \\
\text { PARTICIPACIÓN }\end{array}$ \\
\hline 1986 & 560.1 & 2.702 .3 & 20.7 \\
1987 & 713.6 & 2.517 .0 & 28.4 \\
1988 & 717.9 & 2.539 .6 & 28.3 \\
1989 & 774.6 & 2.457 .3 & 31.5 \\
1990 & 1.019 .2 & 3.200 .7 & 31.8 \\
1991 & 1.314 .4 & 4.057 .1 & 32.4 \\
1992 & 1.957 .2 & 4.880 .6 & 40.1 \\
1993 & 2.880 .7 & 6.033 .7 & 47.7 \\
1994 & 3.464 .7 & 7.547 .0 & 45.9 \\
1995 & 4.589 .0 & 10.011 .0 & 45.8 \\
\hline
\end{tabular}

Fuente: Informes de la Gestión Financiera del Estado $M$ de Hacienda.

*: Incluye timbres e I.V.A. 


\section{Análisis del comportamiento de los ingresos no tributarios}

Años 1986-1996

Los ingresos No Tributarios están compuestos por rentas de activos fijos y financieros, venta de artículos estancados en aduanas, utilidades de Empresas Estatales, tasas, derechos y cargos por servicios.

El poco aporte de los Ingresos No Tributarios a la caja fiscal, sugiere una revisión y actualización del precio de los servicios por los que el Gobiemo presta; pero también debe acompañarse de medidas que ofrezcan mayor eficiencia en la prestación de los mismos. En el cuadro $\mathrm{N}^{2} 7$ se muestra el comportamiento de los Ingresos No Tributarios.

\section{Cuadro N2 7}

Relación ingresos no tributarios - ingresos corrientes

(Millones de colones)

\begin{tabular}{|c|c|c|c|c|}
\hline AÑOS & $\begin{array}{c}\text { INGRESOS } \\
\text { TRIBUTARIOS }\end{array}$ & $\begin{array}{c}\text { INGRESOS NO } \\
\text { TRIBUTARIOS }\end{array}$ & $\begin{array}{c}\text { INGRESOS } \\
\text { CORRIENTES }\end{array}$ & $\begin{array}{c}\text { COEFICIENTE } \\
\text { YNT/YC }\end{array}$ \\
\hline 1986 & 2.702 .3 & 272.0 & 3.007 .2 & 9.0 \\
1987 & 2.517 .0 & 163.9 & 2.720 .8 & 6.0 \\
1988 & 2.539 .6 & 199.0 & 2.811 .3 & 7.0 \\
1989 & 2.457 .2 & 120.9 & 2.623 .5 & 4.6 \\
1990 & 3.200 .7 & 109.0 & 3.367 .0 & 3.2 \\
1991 & 4.057 .1 & 168.2 & 4.362 .8 & 3.8 \\
1992 & 4.880 .6 & 310.6 & 5.354 .7 & 5.8 \\
1993 & 6.033 .7 & 409.6 & 6.549 .1 & 6.2 \\
1994 & 7.547 .0 & 877.8 & 8.573 .8 & 10.2 \\
1995 & 10.011 .7 & 499.0 & 10.657 .9 & 4.6 \\
1996 & 10.465 .1 & 273.9 & 11.019 .3 & 2.5 \\
\hline
\end{tabular}

Fuente : Informes de la Gestión Financiera del Estado. M. de Hacienda

YNT: Ingreso no tributario

YC: Ingresos corrientes

\section{Análisis del comportamiento de las donaciones.}

Del total de donaciones recibidas durante el periodo (1986-1996), las destinadas al presupuesto ordinario se utilizaron principalmente para financiar gastos corrientes. Para fiananciar el presupuesto extraordinario se destinó \&3,011.9 millones y para el Plan de Reconstrucción Nacional $₫ 1,457.9$ millones.

Las Donaciones son ingresos sin contrapartida, producto de la solidaridad internacional, debido principalmente al proceso de inestabilidad social, la tendencia del ingreso por donaciones es decreciente a partir de 1994, debido a que 
el país entra en una relativa paz social a partir de los acuerdos de Chapultepec. El cuadro $N^{0} 8$ indica el comportamiento de las Donaciones.

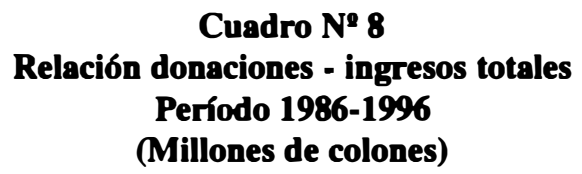

\begin{tabular}{|c|c|c|c|}
\hline AÑOS & DONACIONES & $\begin{array}{l}\text { INGRESOS } \\
\text { TOTALES }\end{array}$ & $\begin{array}{l}\text { DONACIONES/ } \\
\text { INGRESOS TOTALES }\end{array}$ \\
\hline 1986 & 311.8 & 3.603 .6 & 8.65 \\
1987 & 545.7 & 3.232 .6 & 16.88 \\
1988 & 542.0 & 3.175 .5 & 17.06 \\
1989 & 522.6 & 3.330 .2 & 15.70 \\
1990 & 869.3 & 4.792 .7 & 18.13 \\
1991 & 850.9 & 5.783 .0 & 14.71 \\
1992 & 962.0 & 6.956 .6 & 13.82 \\
1993 & 1224.0 & 8.126 .5 & 15.06 \\
1994 & 971.7 & 11.418 .6 & 8.50 \\
1995 & 801.7 & 12.317 .0 & 6.50 \\
1996 & 105.2 & 13.750 .2 & 0.76 \\
\hline
\end{tabular}

Fuente : B.C.R. Revista trimestral, varios números estadísticas BCR. M de Hacienda

\section{Análisis del comportamiento del endeudamiento interno}

Las letras del tesoro público "LETES", como fuente de financiamiento a corto plazo

Hasta 1993, la fuente que el Ministerio de Hacienda utilizó para financiar las deficiencias temporales de caja fiscal, fueron los préstamos concedidos por el Banco Central de Reserva a un año plazo, denominados "Adelantos de Tesorería (AT)", los que generalmente se necesitaban en el último mes del año, debido a que la brecha financiera que se presentaba por el pago de aguinaldos era significativa. Este financiamiento implicaba costos para el Gobiemo, ya que se obtenía recursos a tasas de interés del $17 \%$ y el $19 \%$ anual.

Con las reformas introducidas a la ley Orgánica del Banco Central de Reserva, en el año de 1994, específicamente con la derogatoria del artículo $\mathrm{N}^{2} 74$ de dicha ley, el Banco eliminó la posibilidad de conceder créditos destinados a cubrir las deficiencias transitorias de la caja de Tesorería General de la República; dejando la posibilidad de poder hacerlo solamente hasta 1995, siempre y cuando lo permita el programa monetario. 
Características de las LETES.

Las Letras del Tesoro son colocadas a descuento pagaderas a su fecha de vencimiento, o si el Ministerio de Hacienda lo estima conveniente pueden redimirse anticipadamente, siempre y cuando los tenedores estén dispuestos a redimirlas antes del vencimiento. Las Letras del Tesoro, están exentas de todo tipo de impuestos fiscales y municipales, no se emiten a plazos mayores de un año, por lo que no esta considerada como deuda pública del Gobiemo ya que son instrumentos de financiamiento temporal de caja; clasificándose en consecuencia dentro de la categoría de deuda flotante.

A raíz de la declaración y pago del Impuesto sobre la Renta durante el mes de mayo de 1995, la disponibilidad de Tesorería mejoró, por lo que se consideró conveniente reducir los costos financieros por concepto del descuento de las LETES, redimiendo aquellas con vencimiento en los meses de junio, julio y agosto de ese año, en vista de que muchos inversionistas estaban dispuestos a hacerlo.

\section{Cuadro No 9}

Primera emisión y colocación de LETES por plazos.

(En colones)

\begin{tabular}{|c|c|c|c|c|c|}
\hline \multirow[t]{2}{*}{ PLAZO } & \multirow[t]{2}{*}{ VALOR NOMINAL } & \multicolumn{2}{|c|}{ TASA DE DESCUENTO } & \multirow[t]{2}{*}{ PRECIO } & \multirow[t]{2}{*}{ DESCUENTO } \\
\hline & & INICIAL & $29-11-94$ & & \\
\hline A 60 & $254,100.000$ & $10.56 \%$ & $11.04 \%$ & $249,470.600$ & $4,629.400$ \\
\hline DLAS & & & & & \\
\hline & $64,250.000$ & $10.77 \%$ & $11.24 \%$ & $62,448.393$ & $1,801.606$ \\
\hline DIAS & & & & & \\
\hline $\begin{array}{l}180 \\
\text { DIAS }\end{array}$ & 155.010 .000 & $10.76 \%$ & $11.20 \%$ & $146,436.008$ & $8,573.992$ \\
\hline TOTAL & $473,360.000$ & & & $458,355.001$ & $15,004.998$ \\
\hline
\end{tabular}

Fuente: Dirección General de Tesorería. M. de Hacienda.

\section{Cuadro N ${ }^{2} 10$}

Segunda emisión y colocación de LETES por plazo. Febrero de 1995 (En colones)

\begin{tabular}{|l|c|cc|c|r|}
\hline PLAZO & VALOR NOMINAL & \multicolumn{2}{|c|}{ TASA DE DESCUENTO } & PRECIO & DESCUENTO \\
& & INICLAL & $08-03-95$ & & \\
A 90 & $248,860.000$ & $10.66 \%$ & $11.47 \%$ & $242,327.000$ & $6,532.910$ \\
DIAS & & & & & \\
120 & $182,770.000$ & $10.66 \%$ & $10.56 \%$ & $176,336.322$ & $12,966.587$ \\
DIAS & & & & & \\
TOTAL & $431,630.000$ & & & $418,663.412$ & $19,499.497$ \\
\hline
\end{tabular}

Fuente: Dirección General de Tesorería. M. de Hacienda. 


\section{Análisis del endeudamiento externo}

El endeudamiento Extemo se realiza a través de la contratación de préstamos con diversos agentes de la Banca Internacional y organismos multilaterales de créditos extranjeros.

Para el análisis del comportamiento del endeudamiento se utiliza como parámetro el coeficiente servicio de la deuda / PIB.

Cuadro No 11

Servicio de la deuda pública (Millones de colones)

\begin{tabular}{|c|c|c|c|c|c|}
\hline AÑOS & AMORTIZACIÓN & INTERESES & $\begin{array}{c}\text { SERVICIO } \\
\text { DEUDA }\end{array}$ & P.I.B. & $\begin{array}{c}\text { COEFICIENTE } \\
\text { SD / PIB }\end{array}$ \\
\hline 1986 & 475.1 & 265.4 & 741.1 & $19,762.9$ & 3.7 \\
1987 & 339.5 & 241.2 & 580.7 & 23.140 .6 & 2.5 \\
1988 & 302.8 & 243.8 & 546.6 & 27.365 .8 & 2.0 \\
1989 & 325.6 & 287.6 & 613.2 & 32.072 .7 & 1.9 \\
1990 & 185.1 & 310.1 & 495.2 & 36.486 .9 & 1.3 \\
1991 & 247.0 & 527.5 & 774.5 & 42.594 .2 & 1.8 \\
1992 & 706.8 & 1072.3 & $1,779.1$ & 49.840 .6 & 3.5 \\
1993 & 670.5 & 1024.0 & $1,694.5$ & 60.523 .0 & 2.8 \\
1994 & 1032.5 & 1131.0 & $2,163.5$ & 70.771 .0 & 3.0 \\
1995 & 1079.2 & 1188.5 & $2,267.7$ & 84.524 .0 & 2.6 \\
1996 & 1373.5 & 1346.0 & $2,723.5$ & 92.554 .0 & 2.9 \\
\hline
\end{tabular}

Fuente: Informes anuales de la Gestión Financiera del Estado.

SD: Servicios de la deuda.

La tendencia cambia en 1992 y es siempre alcista, debido a la Renegociación de la Deuda en ese año en el Club de Paris, y la deuda interna también se consolida. Pero en general, el bajo coeficiente Servicio Deuda / PIB indica poco riesgo para el país, influyendo en este omportamiento la condonación de la Deuda por parte de los Estados Unidos de América y de Canadá.

\section{Tercera parte}

Análisis de las tendencias de las fuentes de ingreso y/o financiamiento del gasto público en El Salvador 1986-1996.

Para el análisis de las tendencias de las fuentes de Ingreso y Financiamiento en el caso de El Salvador, es necesario considerar varios elementos, entre ellos: el Gasto Público, los Ingresos al Tesoro, el Déficit Fiscal y las Implicaciones Macroeconómicas, según el tipo de financiamiento. 


\section{a) El gasto público}

La tendencia de todo el periodo es incrementalista, tanto en los gastos corientes como en los de capital. En los gastos corrientes, en el rubro salarios el Gobierno dedicó cada año mas y mas a este rubro, es de reconocer que la firma de los acuerdos de Paz creo nuevas instituciones y presionó hacia el alza. Los efectos de decretos de despido de empleados públicos, tales como el Decreto Legislativo 111 en 1992 y el 471 en 1995, no reflejan cambios sustantivos en la tendencia.

Llama la atención el rubro de Bienes y Servicios, el cual no guarda proporción con el de salarios, lo que se traduce en servicios deficientes a la población, El rubro de intereses aumenta sustantivamente a partir de 1992, producto de la renegociación de la Deuda Extema.

El comportamiento del Gasto Público lo muestra el cuadro № 12 .

\section{Cuadro N² 12 \\ Clasificación \\ (Millones de colones) \\ GASTOS CORRIENTES.}

\begin{tabular}{|c|c|c|c|c|c|c|}
\hline AÑOS & SALARIOS & $\begin{array}{l}\text { BIENES Y } \\
\text { SERVICIOS }\end{array}$ & INTERESES & \multicolumn{2}{|c|}{ TRANSFERENCIAS } & TOTAL \\
\hline 1986 & 1.456 .9 & 298.9 & 260.0 & 404.0 & 58.0 & 2.477 .8 \\
\hline 1987 & 1.676 .6 & 288.8 & 241.3 & 282.2 & 58.0 & 2.546 .9 \\
\hline 1988 & 1.713 .1 & 290.3 & 243.9 & 361.1 & 82.0 & 2.690 .6 \\
\hline 1989 & 2.030 .1 & 323.0 & 207.7 & 364.1 & 130.4 & 3.135 .3 \\
\hline 1990 & 2.307 .9 & 388.2 & 310.1 & 449.4 & 112.1 & 3.567 .7 \\
\hline 1991 & 2.548 .7 & 432.4 & 527.6 & 603.7 & 124.3 & 4.236 .7 \\
\hline 1992 & 2.639 .0 & 591.0 & 1072.3 & 535.2 & 330.7 & 5.169 .0 \\
\hline 1993 & 3.003 .0 & 751.4 & 1024.1 & 852.6 & 537.8 & 6.168 .9 \\
\hline 1994 & 3.518.7 & 979.3 & 1131.1 & 1269.0 & 1057.6 & 7.955 .7 \\
\hline 1995 & 4.286 .6 & 1174.7 & 1188.5 & 1233.0 & 1648.3 & 9.531 .1 \\
\hline 1996 & 4.815 .8 & 1455.7 & 1346.1 & 1294.8 & 1145.6 & 10.058 .0 \\
\hline
\end{tabular}

Fuente: Informes complementarios de la Gestión Financiera del Estado

\section{B) Los ingresos al tesoro}

El comportamiento de los ingresos al Tesoro se analiza a partir de la carga tributaria, la cual ha mantenido tendencia alcista a partir del año de 1989; en parte como producto de las reformas al sistema tributario y a algunas medidas que mejoraron la administración de los impuestos y al comportamiento de la economía Nacional. 


\section{Cuadro N2 13 \\ CARGA TRIBUTARIA EN EL SALVADOR PERIODO 1986-1995. \\ (Millones de colones)}

\begin{tabular}{|c|c|c|c|}
\hline AÑOS & $\begin{array}{c}\text { INGRESOS } \\
\text { TRIBUTARIOS }\end{array}$ & $\begin{array}{c}\text { PRODUCTO } \\
\text { INTERNO BRUTO }\end{array}$ & $\begin{array}{c}\text { CARGA } \\
\text { TRIBUTARIA\% }\end{array}$ \\
\hline 1986 & 2.702 .3 & $19,762.9$ & 13.7 \\
1987 & 2.517 .0 & 23.140 .6 & 10.9 \\
1988 & 2.539 .6 & 27.365 .8 & 9.30 \\
1989 & 2.457 .3 & 32.072 .7 & 7.70 \\
1990 & 3.200 .7 & 36.486 .9 & 8.70 \\
1991 & 4.057 .1 & 42.594 .2 & 9.50 \\
1992 & 4.880 .6 & 49.840 .6 & 9.80 \\
1993 & 6.033 .6 & 60.523 .0 & 10.0 \\
1994 & 7.547 .0 & 70.771 .0 & 10.7 \\
1995 & 11.011 .3 & 84.524 .0 & 11.8 \\
1996 & 10.465 .1 & 92.554 .10 & 11.3 \\
\hline
\end{tabular}

Fuente: Informes anuales de la Gestión Financiera del Estado.

CARGA TRIBUTARIA EN AMÉRICA LATINA. 1988-1989

\begin{tabular}{|l|c|l|c|}
\hline \multicolumn{1}{|c|}{ PAÍS } & $\begin{array}{c}\text { CARGA } \\
\text { TRIBUTARIA }\end{array}$ & \multicolumn{1}{|c|}{ PAÍS } & $\begin{array}{c}\text { CARGA } \\
\text { TRIBUTARIA }\end{array}$ \\
\hline 1. CHILE & 24.06 & 10.-ECUADOR & 15.38 \\
2. URUGUAY & 22.76 & 11.-HONDURAS & 13.03 \\
3. COSTA RICA & 22.39 & 12.-REP.DOMINIC. & 12.97 \\
4. NICARAGUA & 19.83 & 13.-COLOMBIA & 11.69 \\
5. ARGENTINA & 19.59 & 14.-PARAGUAY & 8.87 \\
6. MEXICO & 18.75 & 15.-BOLIVIA & 8.32 \\
7. BRASIL & 17.71 & 16.-PERU & 7.90 \\
8. PANAMA & 17.43 & 17.-GUATEMALA & 7.84 \\
9. VENEZUELA & 15.42 & 18.-EL SALVADOR & 7.79 \\
\hline
\end{tabular}

Fuente: Informes administración tributaria de los impuestos internos en El Salvador, julio Roberto Piza 1994.

Para efectos comparativos se muestra para los años 1988 y 1989 la carga tributaria en varios países de Latinoamérica, El Salvador tenía una carga baja. Una carga Tributaria baja, no indica necesariamente que hay que aumentar impuestos, se debe buscar la causa de este comportamiento. 
Si en la estructura anterior se introduce el valor de la carga tributaria de 11.8\% que corresponde al año de 1995 que es la mas alta del periodo estudiado, ascenderíamos sin actualizar ningún dato del resto de países, a la posición $\mathrm{N}^{\mathfrak{2}} 13$.

Las tendencias de los ingresos aunque alcistas son afectadas por fenómenos como son la Evasión y Elusión Fiscal y es uno de los principales elementos que atentan contra el sistema tributario, ya sea en Renta, IVA o Comercio Exterior.

En el caso particular del IVA, Roberto Rivera Campos, en un estudio de Evasión indicó que por ejemplo los sectores comercio y manufactura evadían el $26 \%$ y $23 \%$ respectivamente.

Por el lado de la Elusión Fiscal la fragilidad del sistema salvadoreño se refleja en la facilidad de interponer recursos de apelación a una instancia, llamada tribunal de apelaciones, que con solo aceptarla se suspende la acción de pago de impuestos.

\section{c) El défícit fiscal}

La tendencia del periodo (1986-1996), del Déficit Fiscal es decreciente durante los últimos cuatro años del estudio. En el caso salvadoreño, las donaciones han contribuido sustantivamente a financiar el gasto público, el problema surge porque las Donaciones son cada vez menores, lo que puede cambiar este comportamiento decreciente.

\section{Cuadro N214 \\ El déficit El Salvador \\ Sector público financiero \\ (Millones de colones)}

\begin{tabular}{|l|r|r|}
\hline AÑOS & $\begin{array}{l}\text { DÉFICIT } \\
\text { CON DONACIONES }\end{array}$ & $\begin{array}{l}\text { DÉFICIT } \\
\text { SIN DONACIONES }\end{array}$ \\
\hline 1986 & 99.9 & 411.9 \\
1987 & 67.9 & 655.7 \\
1988 & 379.9 & 921.9 \\
1989 & 1.344 .1 & 1.876 .7 \\
1990 & 147.0 & 1.031 .0 \\
1991 & 1.201 .0 & 2.082 .0 \\
1992 & 2.275 .0 & 3.241 .0 \\
1993 & 980.0 & 2.204 .0 \\
1994 & 470.2 & 1.390 .4 \\
1995 & 110.7 & 789.5 \\
1996 & 2.167 .9 & 2.330 .0 \\
\hline
\end{tabular}

Fuente: Revista trimestral B.C.R., varios números. 
Las posibles implicaciones macroeconómicas según la fuente de financiamiento utilizado

En El Salvador se han utilizado varios tipos de financiamiento del Déficit Público, entre ellos esta:

i) El Endeudamiento con el Banco Central de Reserva.

El mecanismo utilizado por el gobiemo en este caso se llama Adelanto de Tesorería (AT) y los efectos macroeconómicos se ven muy influenciados por el aumento de la base monetaria. Al parecer este tipo de financiamiento fue utilizado entre los años 1986-1990; las presiones inflacionarias se vieron reflejadas en la tasa de inflación, en 1990 marcaba la inflación una tasa del 24\%. De todos es conocido los efectos nocivos de la inflación, particularmente en los sectores de menos recursos económicos, ya que su ingreso real cae severamente, en este periodo se deterioró mas la situación económica de estos grupos.

El uso de este mecanismo como fuente de financiamiento, es altamente perjudicial por los desbalances económicos que genera en la economía salvadoreña.

ii) Uso de endeudamiento Interno, con el Sector Privado.

Este mecanismo tiene como efecto principal producir un efecto desplazamiento de la inversión, ya que reduce el crédito disponible para el sector privado $e$ induce a un aumento de la tasa de interés real. El uso de las LETES en El Salvador, forma parte del endeudamiento interno, por ser de corto plazo, forma parte de la deuda flotante.

El uso de financiamiento del déficit a través de LETES, esta muy vinculado a la liquidez del sector privado, si este tiene un exceso de ella, la compra de LETES lo beneficiaría, porque gana el llamado redescuento, por el contrario, si el sector privado tiene liquidez limitada, la compra de LETES, contribuye a mantener alta la tasa de interés, lo que afecta la inversión.

\section{Cuarta parte}

\section{Conclusiones}

Aparentemente en El Salvador no existe una política de reducción del Gasto Público; a nuestro criterio es importante que el gobiemo formule una Política nacional del Gasto Público y entre los elementos mas importantes debería incluir un combate frontal a la compción, ya que ésta, en el ámbito económico altera la eficacia de las políticas públicas, pues es un elemento que distorsiona la asignación de recursos e impide una sana competencia, afectando el Gasto Público, los sistemas impositivos y aduaneros.

Desde el punto de vista político, la comupción erosiona la credibilidad de las instituciones públicas, la sociedad civil debe fortalecerse para contribuir a la 
sana critica. Ningún proyecto de Nación es sostenible si existe corrupción.

Para el reclutamiento de servidores públicos, es necesario crear un órgano independiente de selección y evaluación de personal, para proponer además de estímulos económicos, se deben adicionar los de prestigio.

El estudio ha indicado que el Sistema tributario Salvadoreño pasó de un sistema inelástico a uno elástico en ello las reformas incidieron; que además contribuyeron a profundizar la regresividad del sistema; es decir, los impuestos como el IVA y al Comercio Exterior, representan la mayor parte de la Carga tributaria.

Otro aspecto relativamente estudiado como amenaza a los ingresos al tesoro es la Evasión y Elusión Fiscal, en el caso del Impuesto sobre la Renta, las profesiones liberales son dificiles de controlar por la autoridad fiscal, los sectores comercio, industria y otros toman porcentajes relevantes. Por tanto es necesario que haya voluntad política para penalizar al evasor, existen ya modificaciones al código Procesal Penal, que tipifica el delito fiscal; pero hasta la fecha no han existido casos ejemplarizantes de castigo al evasor. Por el lado de la Elusión fiscal es necesario un código tributario que elimine vacios legales, que solo fomentan la Evasión.

En El Salvador, el no pagar impuestos está vinculado a una costumbre generalizada de la sociedad civil, y es la cultura de la Evasión; es necesario, hacer esfuerzos educacionales para cambiar este comportamiento proclive a la Evasión de una manera sistemática.

El gobiemo deberia realizar reformas a las leyes penales y considerar que eludir la obligación tributaria con la intención de evadir impuestos, es por si misma una evasión.

El comportamiento de los impuestos dependen en gran medida de la evolución positiva del P.I.B., para contribuir a este propósito el Gobiemo debe ejecutar un programa de inversiones públicas sostenido a fin de complementar los esfuerzos que en este rubro realiza el sector privado.

Finalmente el sector privado debe comprender que pagar impuestos es la única forma de financiar el Crecimiento y Desarrollo Económico y los que tienen el poder político deben contribuir cuidando de no derrochar el dinero de todos los Salvadoreños y solo asi alcanzaremos el desarrollo necesario para mejorar el nivel de vida de todos los que vivimos en El Salvador. 